Jurnal Pemberdayaan: Publikasi Hasil Pengabdian kepada Masyarakat

Vol. 2, No. 3, Desember 2018, Hal. 407-412

ISSN: 2088 4559; e-ISSN: XXXX-XXXX

DOI:

\title{
PELATIHAN PEMBUATAN MEDIA PEMBELAJARAN UNTUK PERWAKILAN GURU SD/MI PADA BADAN KERJASAMA SEKOLAH (BKS) SD/MI MUHAMMADIYAH/ AISYIYAH KABUPATEN BANTUL
}

\author{
Lisna Zahrotun ${ }^{1}$, Arfiani Nur Khusna ${ }^{2}$, Rusydi Umar ${ }^{3}$ \\ Universitas Ahmad Dahlan, Yogyakarta ${ }^{1,2,3}$ \\ Email: lisna.zahrotun@tif.uad.ac.id ${ }^{1}$
}

\begin{abstract}
ABSTRAK
Pada era persaingan global saat ini, ilmu pengetahuan dan teknologi berkembang begitu pesat melalui berbagai inovasi-inovasi yang semakin maju seiring dengan perkembangan zaman. Badan Kerjasama Sekolah (BKS) SD/ MI Muhammadiyah/ Aisyiyah Kabupaten Bantul merupakan sebuah wadah dari seluruh SD/ MI Muhammadiyah/ Aisyiyah se Kabupaten Bantul mempunyai program kerja salah satunya mengembangkan dan meningkatkan serta menciptakan daya saing civitas terutama guru SD/ MI Muhammadiyah/ Aisyiyah sehingga tercipta pengajar yang unggul disertai pemanfaatan teknologi untuk peningkatan kualitas belajar dan menunjang pembelajaran. Agar program kerja dari (BKS) SD/ MI Muhammadiyah/ Aisyiyah Kabupaten Bantul dapat berjalan dengan lancar maka dilakukanlah pelatihan pembuatan media pembelajaran untuk $\mathrm{BKS} \mathrm{SD} / \mathrm{MI}$ Muhammadiyah/ Aisyiyah Kabupaten Bantul. Metode yang digunakan dalam pelatihan ini adalah dengan memberikan modul pelatihan, bimbingan dengan cara tutorial, pemberian contoh dan studi kasus dan yang terakhir adalah evaluasi. Dari evaluasi yang dilakukan menggunakan kuesioner dalam pelatihan ini dihasilkan bahwa kemampuan meningkat dengan presentase $80 \%$ dan sudah mencapai standar kompetensi yang telah dibuat sehingga pelatihan ini dapat dikatakan berhasil karena dapat meningkatkan kemampuan dari peserta dalam membuat media pembelajaran.
\end{abstract}

Kata kunci: media pembelajaran, civitas, pelatihan

\begin{abstract}
In the current era of global competition, science and technology are developing so rapidly through various innovations those are increasingly advancing along with the times. School Cooperation Agency (BKS) SD / MI Muhammadiyah/Aisyiyah Bantul Regency is a forum for all Muhammadiyah/Aisyiyah SD/MI as Bantul Regency has a work program, one of which is developing and improving and creating competitiveness of the community especially Muhammadiyah/Aisyiyah elementary/ MI teachers so that created excellent teachers along with the use of technology to improve the quality of learning and support learning. In order for the work program of the Muhammadiyah/Aisyiyah Elementary School (BKS) in Bantul Regency to run smoothly, a training on making learning media for BKS SD/MI Muhammadiyah/Aisyiyah was conducted. The method used in this training is to provide training modules, guidance by means of tutorials, giving examples and case studies and the last is evaluation. From the evaluation carried out using the questionnaire in this training it was produced that the ability increased with a percentage of $80 \%$ and had reached the competency standard that had been made so that this training could be said to be successful because it could improve the ability of participants in making learning media.
\end{abstract}

Keywords: learning media, civitas, training 


\section{PENDAHULUAN}

Pada era persaingan global saat ini, ilmu pengetahuan dan teknologi berkembang begitu pesat melalui berbagai inovasi-inovasi yang semakin maju seiring dengan perkembangan zaman. Kemajuan di dalam bidang pengetahuan dan teknologi telah memberikan pengaruh besar terhadap bidang pendidikan. Banyak di kalangan pendidik yang sudah menggunakan media informasi dan multimedia dalam melakukan pembelajaran. Karena dengan menggunakan media pembelajaran siswa tidak cepat bosan dan dapat dapat mempelajari kembali dengan mudah di rumah.

Badan Kerjasama Sekolah (BKS) SD/ MI Muhammadiyah/ Aisyiyah Kabupaten Bantul merupakan sebuah wadah dari seluruh SD/ MI Muhammadiyah/ Aisyiyah se Kabupaten Bantul, BKS ini mempunyai program kerja salah satunya mengembangkan dan meningkatkan serta menciptakan daya saing civitas terutama guru SD/ MI Muhammadiyah/ Aisyiyah sehingga tercipta pengajar yang unggul disertai pemanfaatan teknologi untuk peningkatan kualitas belajar dan menunjang pembelajaran. Hal ini disebabkan masih minimnya guru-guru yang memiliki kemampuan dalam memebuat media pembelajaran.

Berdasarkan permasalahan yang terjadi pada anggota (BKS) SD/ MI Muhammadiyah/ Aisyiyah Kabupaten Bantul, maka dilakukan pelatihan pembuatan media pembelajaran untuk anggota (BKS) SD/ MI Muhammadiyah/ Aisyiyah Kabupaten Bantul. Dengan kegiatan pelatihan melalui pengabdian masyarakat ini diharapkan dapat memberikan kontribusi dalam peningkatan kualitas belajar di SD/ MI Muhammadiyah/ Aisyiyah Kabupaten Bantul sehingga diharapkan program kerja serta visi misi pembelajaran di lingkungan SD/ MI Muhammadiyah/ Aisyiyah Kabupaten Bantul dapat tercapai

\section{METODE}

Metode yang diterapkan dalam pelatihan ini adalah:

1. Pemberian modul kepada peserta, sehingga peserta lebih mudah dalam menerima dan memahai materi yang diberikan, sehingga kegiatan ini lebih efektif.

2. Tutorial, dalam kegiatan ini peserta diberikan bimbangan tutorial untuk praktikum memanfaatkan komputer dalam membuat media pembelajaran

3. Pemberian contoh dan kasus permasalahan, sehingga diharapkan peserta akan lebih paham dalam membuat media pembelajaran. 
4. Materi, materi dibagi dalam enam sesi dengan tiap sesi berjalan selama 120 menit/2 jam dengan total kegiatan 120 menit/2 jam. Materi merupakan kurikulum 2013, Sekolah Dasar kelas IV, tema Lingkungan.

5. Praktik langsung dilaboratorium, yang dibimbing oleh dosen dan asisten dalam membuat media pembelajaran.

\section{HASIL, PEMBAHASAN, DAN DAMPAK}

\section{HASIL DAN PEMBAHASAN}

Pelaksanaan pelatihan ini dibantu oleh 5 asisten yang terdiri dari 5 mahasiswa. Pelaksanaan pra pelatihan hingga evaluasi berlangsung selama 2 bulan, untuk pelaksanaan pelatihan selama 2 hari yang terdiri dari 6 materi yaitu:

1. Pengenalan Power Point

2. Pembuatan slide master, teks, gambar, audio dan hyper link.

3. Pembuatan animasi percakapan pada Power Point.

4. Pembuatan animasi motion dan audio.

5. Pembuatan cerita film pendek

6. Pembuatan soal dan evaluasi pada Power Point.

Pada saat pelatihan terdiri dari 26 peserta terlihat antusias mengikuti rangkaian pelatihan. Dokumentasi pelatihan ditunjukkan dalam Gambar 1 dan Gambar 2

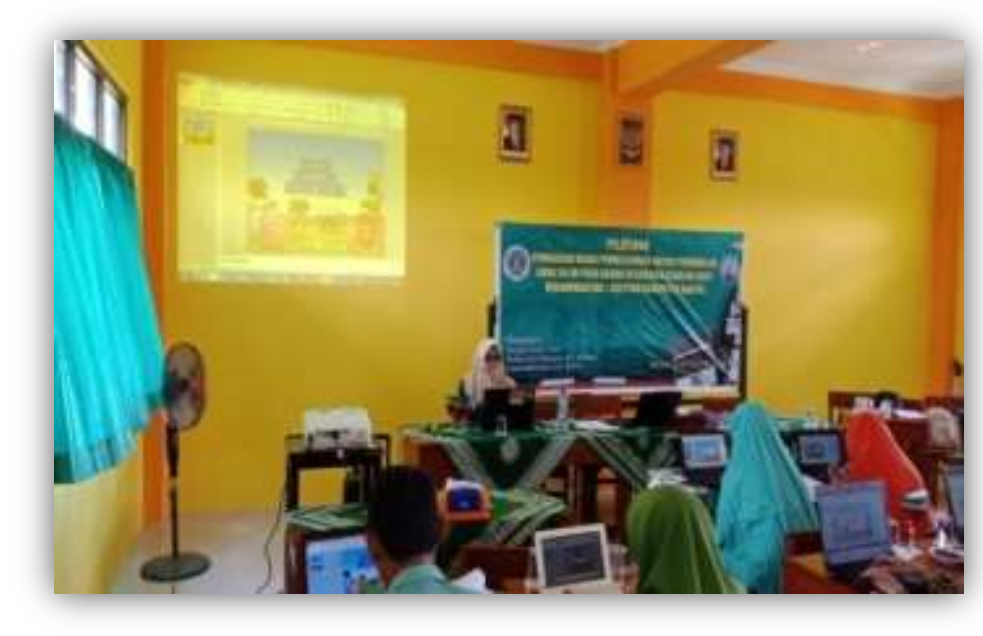

Gambar 1. Dokumentasi pelatihan 


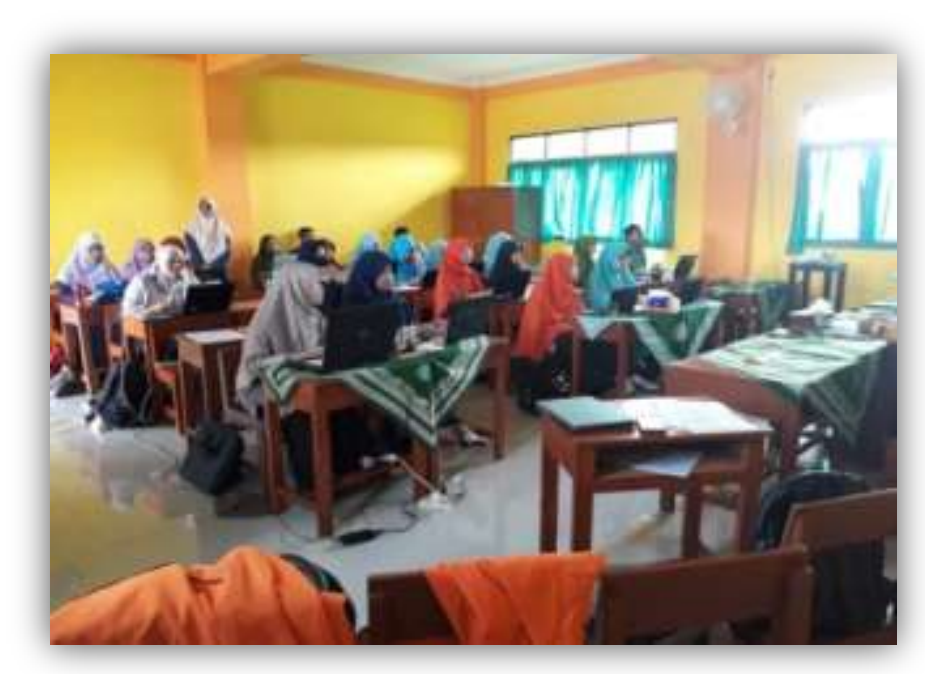

Gambar 2. Proses Pelatihan

Dalam pelatihan ini dilakukan analisis kemampuan peserta menggunakan Adapun penjelasan kuesioner adalah sebagai berikut:

1. Kuesioner sebelum pelatihan

Kuisoner ini bertujuan untuk mengukur kemampuan peserta pelatihan sebelum mengikuti pelatihan Media Pembelajaran Menggunakan Power Point. Berdasarkan hasil kuisoner sebelum pelatihan diketahui:

Anggota Pelatihan : 26 orang

Soal Kuisoner : : 10 soal

Point soal $\quad:$ STS $=1, \mathrm{TS}=2, \mathrm{~S}=3, \mathrm{SS}=4$

$$
\text { Hasil kuesioner sebelum pelatihan }=\frac{650}{26}=25 \quad=25 \%
$$

2. Kuesioner sesudah pelatihan

Kuisoner sesudah pelatihan bertujuan untuk melihat perkembangan kemampuan dari anggota pelatihan. Kuisoner ini dapat membandingkan antara kemampuan peserta pelatihan sebelum dan sesudah mengikuti pelatihan serta dapat melihat tingkat keberhasilan dari pelatihan Media pembelajaran Menggunakan Power Point. Berdasarkan hasil kuisoner sesudah pelatihan diketahui:

Anggota Pelatihan : 26 orang

Soal Kuisoner $\quad: 10$ soal

Point soal $\quad:$ STS $=1, \mathrm{TS}=2, \mathrm{~S}=3, \mathrm{SS}=4$

$$
\text { Hasil kuesioner sesudah pelatihan }=\frac{1950}{1326}=75=75 \%
$$


Dari hasil analisis kuesioner sebelum dan sesudah pelatihan maka dapat dilihat bahwa kemampuan dari peserta naik menjadi $75 \%$. Sehingga pelatihan ini dapat dikatakan berhasil karena dapat meningkatkan kemampuan dari peserta dalam membuat media pembelajaran.

3. Hasil media pembelajaran peserta

a. Ratna Setyowati

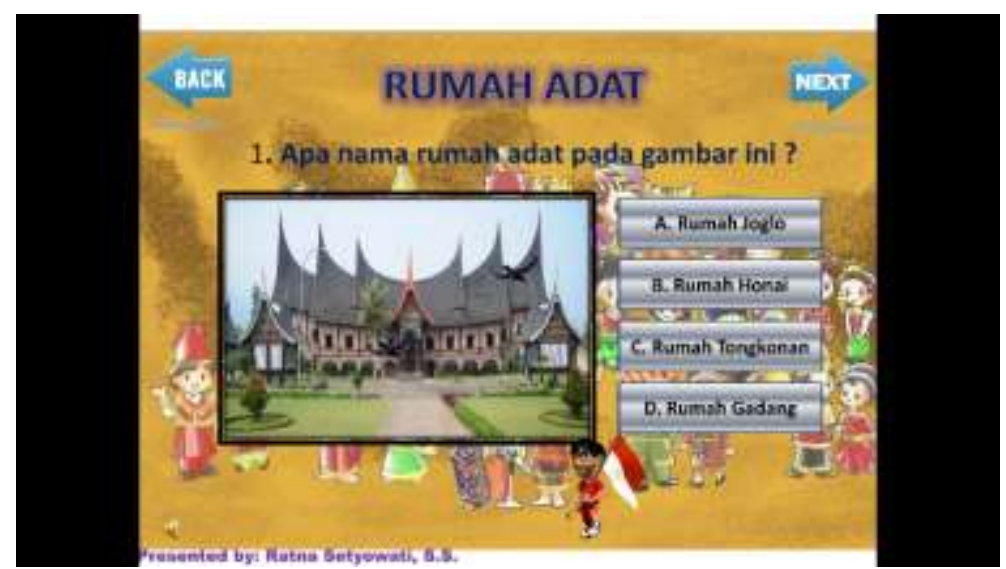

Gambar 3. Media pembelajaran Ratna Setyowati

b. Erna Sulistiowati

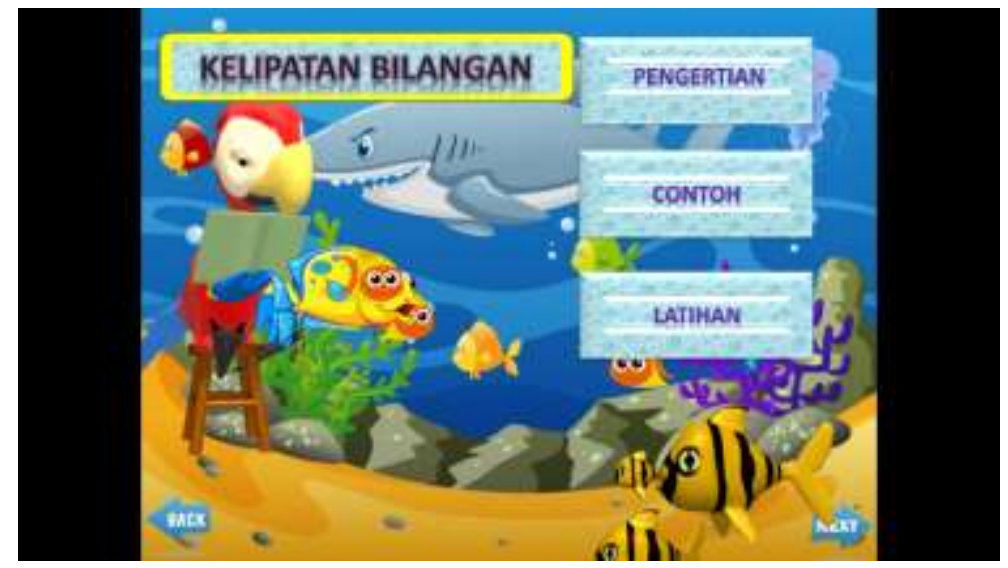

Gambar 4. Media pembelajaran Erna Sulistowati

c. Nur Laili Latifah

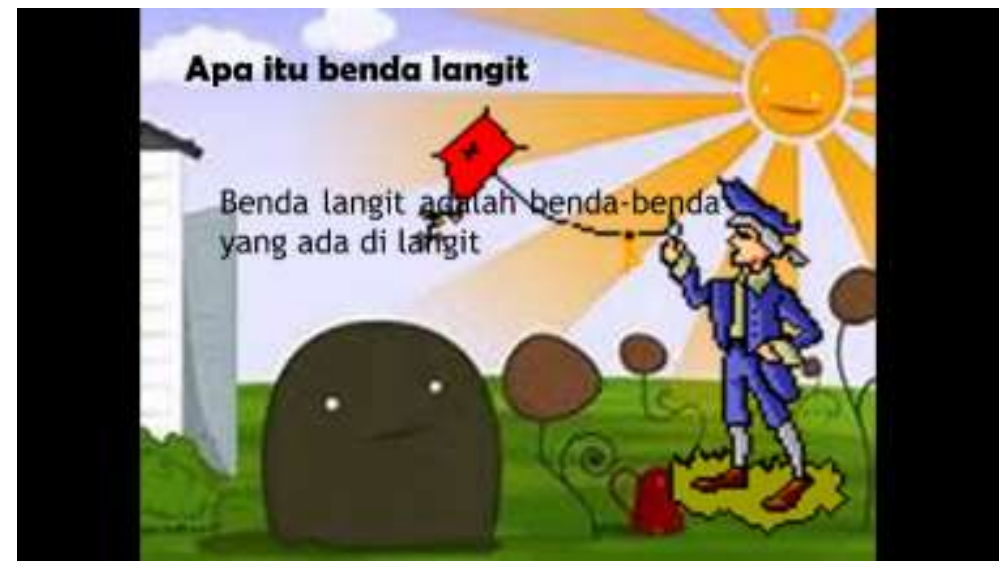

Gambar 5. Media Pembelajaran Nur Laili Latifah 


\section{DAMPAK}

Dampak diadakannya pelatihan pembuatan media pembelajaran Power Point yaitu:

1. Membantu meningkatkan penggunaan alat TIK pada SD/MI Muhammadiyah/Aisyiyah Kabupaten Bantul agar lebih efektif.

2. Membantu meningkatkan kompetensi guru SD/MI Muhammadiyah/Aisyiyah kabupaten Bantul sehingga tercipta pengajar yang unggul disertai pemanfaatan teknologi untuk peningkatan kualitas belajar dan menunjang pembelajaran.

3. Dapat menerapkan teknologi dalam dunia pendidikan berupa media pembelajaran interaktif untuk proses belajar mengajar.

4. Mengenalkan penggunaan Microsoft Powerpoint sebagai sarana kegiatan belajar mengajar kepada perwakilan guru SD/MI pada Badan Kerjasama Sekolah (BKS) Muhammadiyah/Aisyiyah kabupaten Bantul.

5. Dengan diadakannya kegiatan ini diharapkan para guru SD/MI Muhammadiyah/Aisyiyah kabupaten Bantul mampu mengembangkan sebuah media pembelajaran menggunakan Microsoft Powerpoint secara mandiri sehingga dapat membantu siswa memahami materi secara cepat.

6. Para peserta dapat mengembangkan kemampuan untuk membuat media pembelajaran sesuai dengan mata pelajaran yang di ampu.

\section{SIMPULAN}

Berdasarkan pelatihan yang telah dilaksanakan, maka dapat diperoleh kesimpulan telah dihasilakan modul pelatihan pembuatan media pembelajaran menggunakan power point sebagai acuan perserta dalam membuat media pembelajaran. Pelatihan pembuatan media pembelajaran menggunakan power point dilaksanakan sebanyak 2 kali pertemuan dalam 2 hari. Dari hasil evaluasi, dinilai peserta pelatihan yang dapat membuat media pembelajaran menggunakan power point serta memahami tentang software power point sebanyak $75 \%$. 